\title{
ArcheoSciences
}

Revue d'archéométrie

33 (suppl.) | 2009

Mémoire du sol, espace des hommes

\section{Magnetometry and susceptibility prospecting on Neolithic-early Iron Age sites at Serteya, North- West Russia}

Andrei N. Mazurkevich, Daria Yu. Hookk and Jörg W. E. Fassbinder

\section{OpenEdition}

\section{Journals}

Electronic version

URL: https://journals.openedition.org/archeosciences/1328

DOI: 10.4000/archeosciences. 1328

ISBN: 978-2-7535-1599-4

ISSN: $2104-3728$

Publisher

Presses universitaires de Rennes

\section{Printed version}

Date of publication: 30 October 2009

Number of pages: $81-84$

ISBN: 978-2-7535-0943-6

ISSN: $1960-1360$

\section{Electronic reference}

Andrei N. Mazurkevich, Daria Yu. Hookk and Jörg W. E. Fassbinder, "Magnetometry and susceptibility prospecting on Neolithic-early Iron Age sites at Serteya, North-West Russia", ArcheoSciences [Online], 33 (suppl.) | 2009, Online since 30 October 2011, connection on 01 February 2022. URL: http:// journals.openedition.org/archeosciences/1328 ; DOI: https://doi.org/10.4000/archeosciences.1328 


\title{
Magnetometry and susceptibility prospecting on Neolithic-early Iron Age sites at Serteya, North-West Russia
}

\author{
Andrei N. Mazurkevich*, Daria Yu. Hookk* and Jorg W. E. Fassbinder**
}

Key words: Neolithic, early Iron Age, Bronze Age, magnetic prospection, susceptibility prospection, North-West Russia.

\section{INTRODUCTION}

The first pile-dwelling sites in the northwest of Russia were discovered in 1963 by A.M. Miklyaev (Dolukhanov \& Miklyaev, 1986; Dolukhanov et al., 2004). The Neolithic sites of Serteya were found in 1972 during land-improvement work at the small river Serteya, c. $80 \mathrm{~km}$ north of Smolensk and about $10 \mathrm{~km}$ east of the town of Velizh (left inflow of West Dvina River). Traces of two cultural layers with archaeological material were discovered at this site, evidencing a North Belarus culture, the first stage of the Zhizhitsian culture and the final stage of the Usvyatian culture. In a trench in the river and in the steep bank, multiple dwellings, planks and other structures were found. The expedition of 1973 proved underwater excavations to be the most effective investigations on these sites (Hookk \& Mazurkevich, 2007). In 2007, for the first time magnetometer methods were applied to detect further archaeological structures in the sand on the riverbanks. In 2008, the survey was extended to include susceptibility prospecting on small selected excavation sites.

\section{Prospection methods}

For magnetometer prospection the Scintrex Smartmag SM 4G-special system in duo-sensor configuration in total- field mode was applied (Becker, 1999). In this configuration, the diurnal variations of the Earth's magnetic field are reduced to the mean value of calculated data for a $40 \times 40 \mathrm{~m}$ square. This configuration is very sensitive to artificial and technical disturbances and rapid variations of the Earth's magnetic field. The Serteya site, however, is located far from any modern civilization and technical disturbances; moreover, sunspot activity was at a minimum in 2007-2008. Magnetic prospection was therefore applied very successfully in the total-field mode without further problems. The advantage of such a configuration is twofold: the full range of magnetic anomalies can be detected and extensive layers of magnetically enriched soil can be made visible as well (see Fig. 1b), the disadvantage being that archaeological structures could be superimposed by geology (Fassbinder, 2007). The magnetic susceptibly prospection was performed by an SM-30 instrument (ZH-Instruments, Czech Republic). The magnetometer results of the research in 2007-2008 revealed layers and zones of high settlement activity, but also postholes and fireplaces of two different archaeological types. The first type - archaeological remnants from small islands in the glacial lakes (Serteya 3, 2, XX) with cultural layers in sandy loam dating from early Neolithic (6000-7000 to beginning of 5000 BC) to late Neolithic (3500-3000 BC). The most interesting spots indicated by the magnetic prospection were later excavated.

* The State Hermitage Museum, 34, Dvortsovaya emb., 190000 Saint-Petersburg, Russia (hookk@hermitage.ru).

** Bavarian State Dept.of Monuments and Sites, Hofgraben 4, 80539 Munchen, Germany (joerg.fassbinder@blfd.bayern.de). 


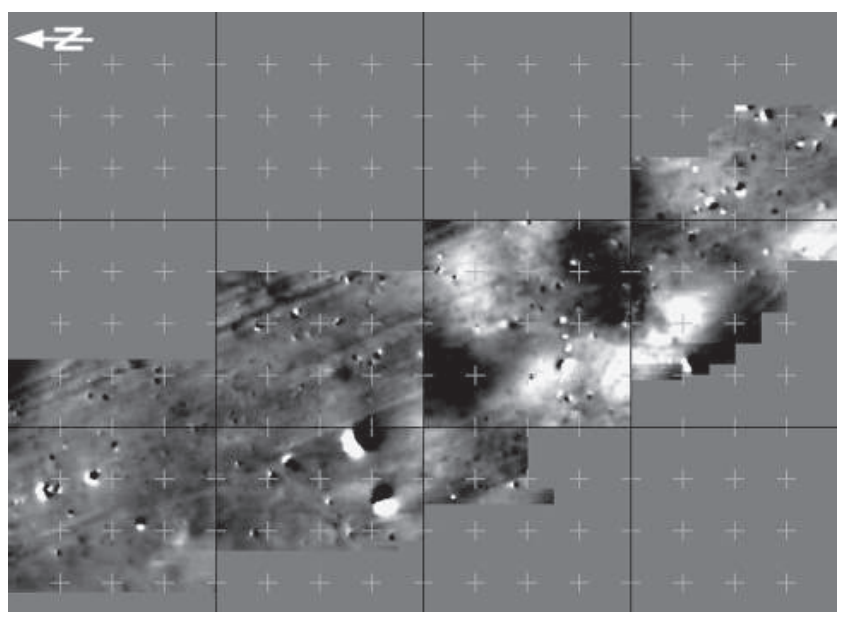

Figure 1a

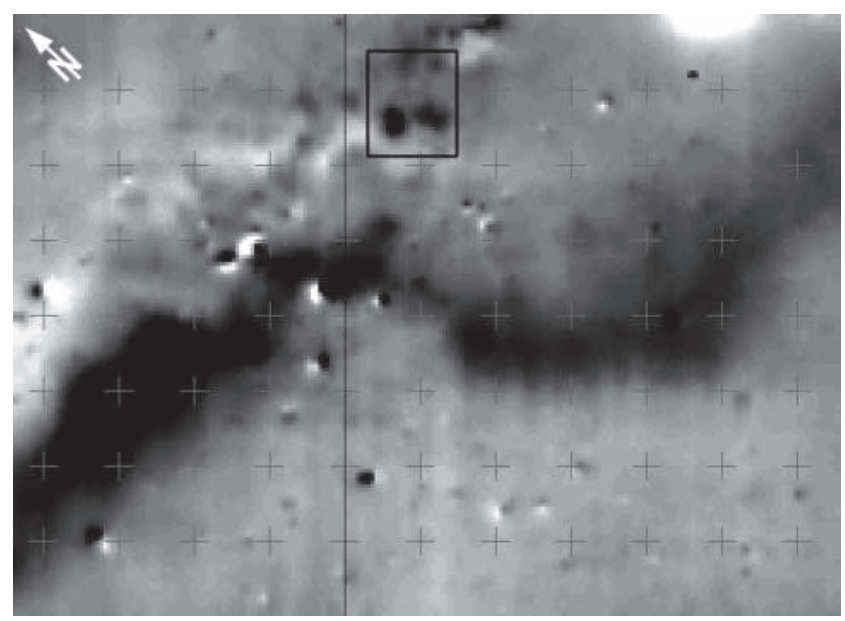

Figure $1 b$

Figures 1a and 1b: Left: Serteya III. Magnetogram of the site showing spots of ancient settlement activity. Right: Serteya $\alpha$. Magnetogram showing a large band of magnetically enriched soil layer (the excavation area is marked by a square). Cesium Smartmag SM-4G Special, duo-sensor configuration, Dynamics +/- 3 Nanotesla, in 256 greyscales, grid size $40 \times 40$ meters, 5 m crosses, sampling rate interpolated to $25 \times 25 \mathrm{~cm}$.

At sites (located in the Kame hills on lake Hollow) where the cultural layers consist of sandy loams and loam (Serteya II-V) archaeological excavations, geochemical analysis, geomorphologic data and topographical data are combined to verify the measured anomalies. Numerous small black spots, of a diameter less than $1 \mathrm{~m}$, reveal ancient fireplaces, light gray circles with a dark spot in the center; these are the remains of small temporal houses with fireplaces (Fig. 1a, left). At the site Serteya $\alpha$ (Fig. 1, right) a large magnetic anomaly (see Fig. 1b) was identified. This anomaly revealed ancient cultural layers which turned out to be dominated by midden deposits and fossil topsoil layers from the ancient ground surface. The magnetic picture revealed also two strong magnetic anomalies indicating ancient kilns or burned structures in the cultural layer in the northern part of the site. This area was selected for excavation (see square in Fig. 1b).

\section{SUSCEPTIBILITY PROSPECTION}

During the excavation the magnetic susceptibility of every layer was measured by a handheld Kappa meter SM-30 (ZH Instruments) with a $20 \times 20 \mathrm{~cm}$ sampling density. For better understanding and a comparison of results with the magnetic prospection, the susceptibility values are visualized in grayscale (Fig. 2a-c). The diameter of the SM30 pick-up coil is only $5 \mathrm{~cm}$. This explains why the susceptibility of each layer shows such a different value. These measurements permitted the different structures of the cultural layers to be recognized on different levels. This correlates perfectly with the independent periods of habitation in the Bronze and Iron Ages. The remains of an early Iron Age structure were detected on the $35 \mathrm{~cm}$ and $45 \mathrm{~cm}$ levels (Fig. 2 a, b; 3), the remains of Bronze Age habitations on the $65 \mathrm{~cm}$ level (Fig. 2 c). Remains of structures destroyed by fire: clay walls, multiple fragments of burned clay and a clay floor, were found on the latter level, representing perhaps a pile dwelling. The cultural layer's specifics, dispersion of stones used presumably to fill the postholes, marked by black-colored ring anomalies, prove the hypothesis. There is an anomaly on the spot of the preserved clay floor (Fig. 2 c).

\section{Conclusion}

By additional measurement of magnetic susceptibility we were able to recognize house extent and structure. A magnetic prospection of this area had revealed only one big spot anomaly, summing up all structures in the cultural layer here. This example demonstrates not only the sensitivity and potential of magnetic methods in general, but also the role of susceptibility measurements in visualizing archaeological structures that cannot be seen with the naked eye. 


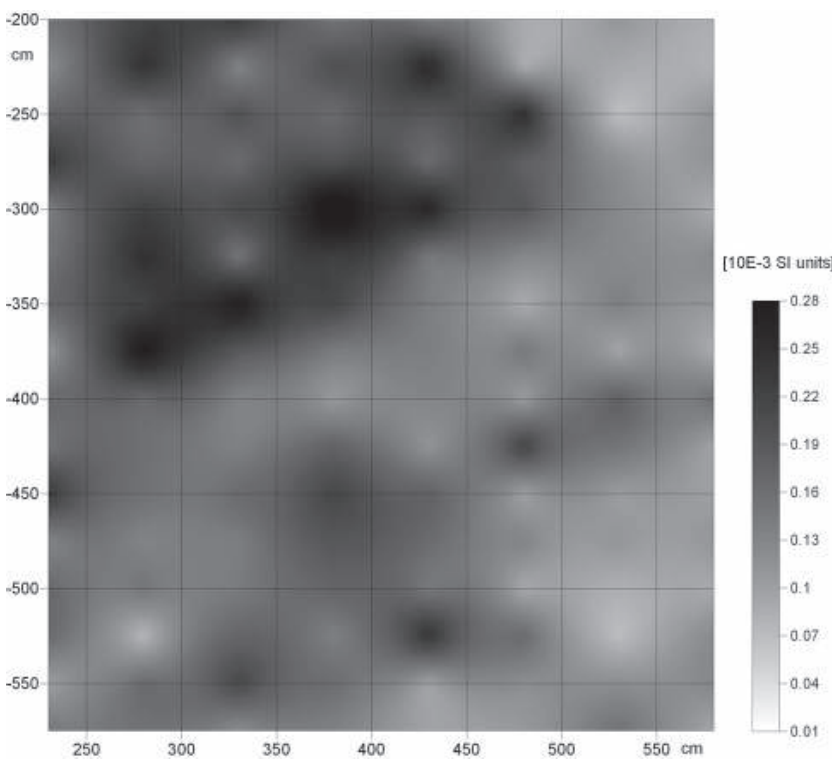

Figure 2a

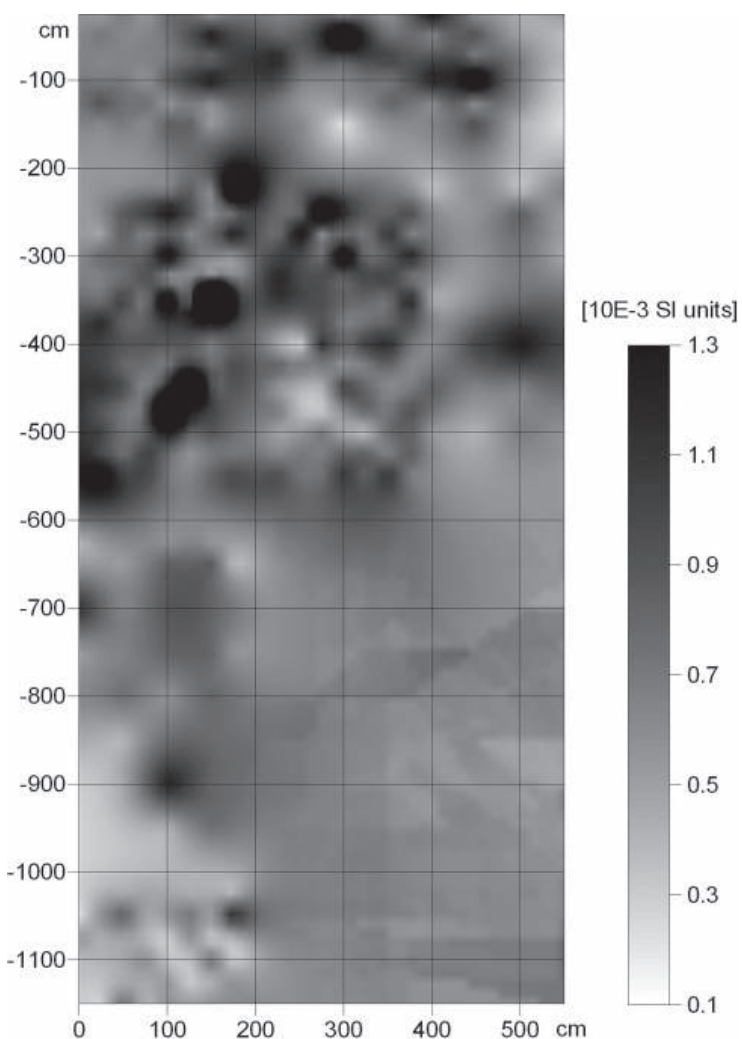

Figure 2c

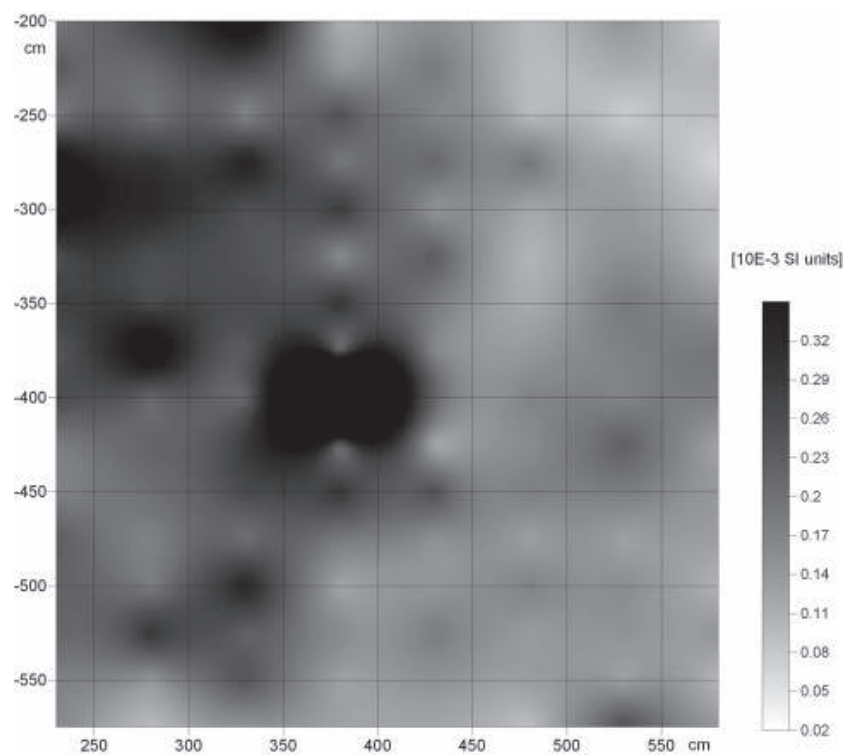

Figure $2 \mathrm{~b}$

Figures 2a, 2b and 2c: Susceptibility prospection at the archaeological site Serteya $\alpha$ on three different levels (a $35 \mathrm{~cm}, \mathrm{~b} 45 \mathrm{~cm}$, c $65 \mathrm{~cm}$ ) of the excavation. Magnetic susceptibility meter SM-30 (ZH Instruments, Czech Republic, sensitivity $\pm 10 \mathrm{E}-7$ SI units, operating frequency $8 \mathrm{kHz}$ ), sampling interval $20 \times 20 \mathrm{~cm}$.

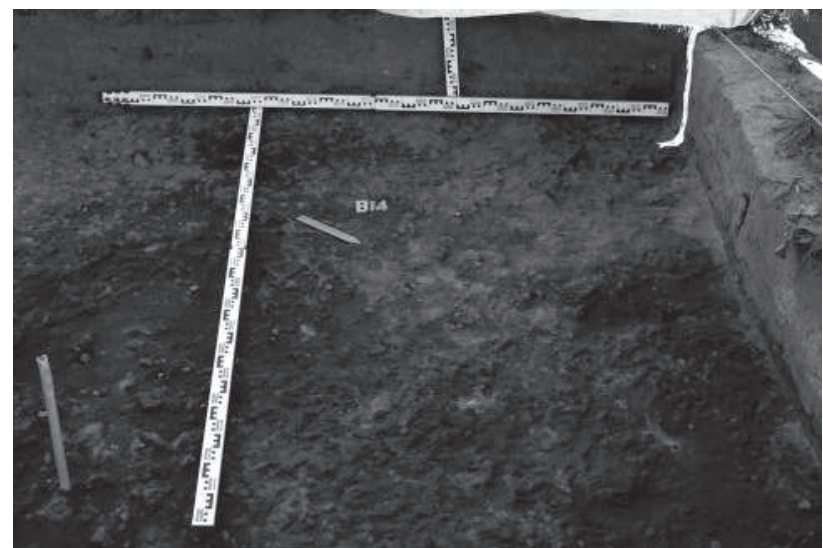

Figure 3: Serteya $\alpha$, layer $45 \mathrm{~cm}$, fragments of burned clay from the early Iron Age period. 


\section{References}

BeCKer, H., 1999. Duo- and quadro-sensor configuration for high-speed/high resolution magnetic prospecting with caesium magnetometer. In: Fassbinder, J. W. E., Irlinger, W. E. (dir.). Archaeological Prospection. Arbeitsh. Bayer. Landesamtf. Denkmalpflege, 108, München, 100-105.

Dolukhanov, P. M. and Miklyaev, A. M., 1986. Prehistoric lacustrine pile dwellings in the north-western part of USSR. Fennoscandia Archaeologica, 6: 81-89.

Dolukhanov, P., Shukurov, K., Arslanov, A. N., Mazurkevich, L. A., Savel'eva, E. N., Dzinoridze, M. A., Kulkova and
G. I., Zaitseva, 2004. The Holocene Environment and Transition to Agriculture in Boreal Russia (Serteya Valley Case Study). Internet Archaeology, 17 (http://intarch.ac.uk/journall issue 17).

Fassbinder, J. W. E., 2007. Unter Acker und Wadi: Magnetometerprospektion in der Archäologie. In Wagner, G. A., (dir.). Einführung in die Archäometrie. Springer, Berlin, Heidelberg, New York, 53-73.

Ноокк, D.Y. and Mazurkevich, A.N., 2007. Fuzzy logic and Neolithic wood. In Mach, M. (dir.). Small Samples big Objects, Proceedings EU-Artech Seminar, 40-50. 